\title{
O ensino superior da História em Portugal (1859-1911)
}

\author{
History in higher education in Portugal (1859-1911)
}

\author{
João Couvaneiro \\ couvaneiro@gmail.com \\ Professor Adjunto com Doutoramento \\ Instituto Piaget \\ Rua Ramiro Ferrão, 29/10D \\ 2805-346 - Almada \\ Portugal
}

\section{Resumo}

Com a realização deste artigo procurei reunir contributos para uma reflexão em torno do processo de surgimento do ensino superior da História em Portugal. Analisei o seu desenvolvimento como área do conhecimento autonomizada, aceite como saber relevante. Visei ampliar o entendimento sobre os mecanismos que conduziram à conquista desse estatuto, sem deixar de ter presente que a disciplinarização não obedece exclusivamente a questões de caráter científico ou acadêmico. Estudei de forma particular o Curso Superior de Letras, criado por D. Pedro V em 1858 e que foi o primeiro estabelecimento português consagrado especificamente ao ensino das ciências sociais e humanas. Com a implantação da República, essa instituição haveria de converter-se na Faculdade de Letras da Universidade de Lisboa, criada em 1910.

\section{Palavras-chave}

\begin{abstract}
With this article I sought to gather contributions for a reflection on the process of the emergence of History in higher education in Portugal. I studied its development as an autonomous area of knowledge that is accepted as relevant knowing. I wanted to broaden the understanding of the mechanisms that led to this status, while bearing in mind that this process did not follow scientific or academic matters exclusively. I focused on the Higher School of Letters, created by D. Pedro $V$ in 1858 , which was the first Portuguese institution specifically devoted to the teaching of social sciences and humanities. With the establishment of the Republic, this institution became the Faculty of Letters of the University of Lisbon, founded in 1910.
\end{abstract}

\section{Keywords}

Portugal; Portuguese historiography; History education.

Enviado em: 14/11/2012

Aprovado em: 29/1/2013 
Os últimos duzentos anos foram marcados pela gradual ampliação do conhecimento histórico e por sua aproximação do grande público. Até às revoluções liberais, a história era reconhecida sobretudo por fornecer quadros morais e exemplos úteis, assentes em narrativas moralizantes, à luz de uma concepção em que essa área do saber surgia como mestra da vida. Com o advento do liberalismo, a percepção de novas necessidades associadas à difusão das memórias nacionais e à legitimação de outras formas de soberania e distintos modelos de organização do Estado reforçaram as exigências que eram impostas à historiografia. Acresce que a laicização da sociedade e a criação de novas elites contribuíram para a multiplicação dos públicos interessados pela cultura erudita, em todas as suas manifestações, e particularmente atentos à história (MARQUES 1988, p. 31). O reconhecimento alargado da sua utilidade social, conjugado com o desenvolvimento do seu quadro epistemológico, contribuiu para que se autonomizasse como disciplina e afirmasse a sua presença em todos os níveis de ensino.

Atento à tendência descrita, Adolfo Coelho afirmou que o século XIX foi sobretudo o século da história. Tal juízo resultava da percepção de que a abordagem historicista tinha dominado todo o espectro do saber, das ciências naturais à filosofia (COELHO 1900, p. 467-468). Porém, em 1900 lamentava que em Portugal o ensino superior da disciplina se encontrasse resumido ao Curso Superior de Letras, enquanto nas nações da Europa culta estava já amplamente representado em faculdades e escolas especiais.

A reforma pombalina da Universidade de Coimbra de 1772 consentiu que nas faculdades de Direito e Teologia fossem lecionados conteúdos históricos que, 163 contudo, surgiam como alicerces propedêuticos para o ensino das áreas nucleares. A autonomização do ensino superior da história em Portugal deu-se apenas com a criação do Curso Superior de Letras, numa iniciativa que revelava algum atraso face a outros países europeus. A título de exemplo, pode referir-se que na Grã-Bretanha data do primeiro quartel do século XVIII a criação de cadeiras de História Moderna nas universidades de Cambridge e Oxford. Na França, foi criada a Faculdade de Letras de Paris em 1808, na qual se instituiu uma cadeira de História Antiga e Moderna. No reino vizinho, foram criadas cátedras de História Geral de Espanha em 1821 (MATOS 1998, p. 172).

O primeiro passo efetivo com vistas à criação do Curso Superior de Letras foi dado por José Maria de Abreu, quem, em abril de 1857, apresentou um Projeto de Lei em que propunha a criação de dois Cursos Superiores de Letras, um para Lisboa e outro para Coimbra. Entre as vantagens que resultariam dessa iniciativa, o propositor destacava o fato de permitir que o magistério da história e de outras ciências humanas não ficasse confinado aos acanhados limites do ensino liceal (ABREU 1857, p. 25).

Foi graças ao empenho de D. Pedro $V$, e por meio da afetação de verbas da sua dotação pessoal, que se viabilizou a criação do Curso Superior de Letras em Lisboa. Por implementar ficou o estabelecimento congênere proposto para Coimbra. Corria o ano de 1859 quando o monarca sancionou o decreto das Cortes que fundava a instituição e estabelecia o plano de estudos. O desenho 
curricular, que vigorou nas duas décadas seguintes, era composto apenas por cinco cadeiras, dispostas em dois anos: História Pátria e Universal; Literatura Grega e Latina e Introdução às suas origens; Literatura Moderna e Especialmente a Portuguesa; Filosofia e História Universal Filosófica.

Regra geral, um novo ponto de vista, uma nova formulação do conhecimento ou uma nova ciência só são admitidos nos estabelecimentos de ensino depois de se terem afirmado fora deles. Nesse sentido, é natural que para a criação da primeira cadeira autónoma de História no ensino superior português, o nome de Alexandre Herculano figurasse como inquestionável, visto que, como afirmou Borges de Macedo, a sua obra representava a conquista em Portugal da maturidade que "os conhecimentos históricos precisavam de ter para serem aceites, tanto pela cultura do seu tempo como pelas instituições responsáveis" (MACEDO 1980, p. 15).

D. Pedro $V$ teria sondado Herculano, no sentido de o fazer aceitar o lugar. Porém, afirmou recear que se fosse ele a assumir a cadeira, «se entretivesse a criar, [...] uma ninhada de municipalistas sem emprego possível» (D. PEDRO V 1930, p. 258). Nesse sentido, o convite pode ter sido apenas circunstancial (COELHO 1910, p. 38; FIGUEIREDO 1910, p. 5; VILHENA 1921, p. 350-353). É até possível que o soberano tivesse, desde o início, a intenção de atribuir a cadeira ao jovem historiador Luís Augusto Rebelo da Silva, que, com méritos reconhecidos, viu nesse mesmo ano ser-Ihe atribuída a responsabilidade de produzir a História de Portugal dos séculos XVII e XVIII (SILVA 1860-1871).

Tendo tomado posse como professor da cadeira de História Pátria e Universal ainda em 1859, pouco mais de uma década durou o vínculo de Rebelo da Silva ao Curso, situação que resultou do seu precoce falecimento (1871), quando contava apenas 49 anos. Não obstante, enquanto integrou o corpo docente, foi a principal referência da instituição. As suas aulas eram autênticos eventos culturais na Lisboa de então, atraindo, para além dos alunos, um público numeroso, fato que obrigou à utilização de instalações da Escola Politécnica, de forma a acomodar confortavelmente todos os ouvintes. No magistério dessa cadeira seguiram-se outros dois nomes assinaláveis no campo intelectual português dos Oitocentos: Augusto Soromenho (1871-1878) e Consiglieri Pedroso (1878-1902).

Em 1901, o Curso Superior de Letras foi reformado, tendo-Ihe sido incutida uma vocação mais profissionalizante. Ampliada a oferta formativa, foram então criados quatro planos de estudos: Geral; Bibliotecário-arquivista; Diplomático; e de Habilitação para o Magistério Liceal. Essa alteração curricular fez aumentar o número de cadeiras de sete para catorze. Aquela em que eram abordados conjuntamente os conteúdos de história universal e de Portugal foi extinta. Em seu lugar, presentes em todos os planos de estudos, foram criadas as cadeiras de História Antiga (10 ano); História da Idade Média e Moderna (20 ano); História Pátria ( $3^{\circ}$ ano). Para os que frequentavam a vertente profissionalizante de ensino existiam ainda: uma cadeira de História da Pedagogia ( $3^{\circ}$ ano) e uma seção especial de História e Geografia (40 ano).

As cadeiras de História Antiga e de História da Idade Média e Moderna tiveram como docentes Consiglieri Pedroso (1902-1904), Oliveira Ramos (1904- 
1911) e Agostinho José Fortes (1910-1911). Já a de História Pátria teve como docentes Consiglieri Pedroso (1903-1910) e Oliveira Ramos (1910-1911).

Do plano de estudos promulgado por D. Pedro V em 1859 fazia parte a cadeira de História Universal Filosófica. O seu magistério coube, inicial e provisoriamente, a Levy Maria Jordão, até que em 1863 se realizou o concurso que levou ao recrutamento de Jaime Moniz. Apesar de, naquela altura, ter se manifestado um espírito prometedor de obras de fôlego, posteriormente, Moniz não as veio a escrever, talvez por ter se deixado absorver pela vida pública, tendo-se tornado uma figura de referência na definição de políticas educativas e na estruturação do sistema de ensino (PEREIRA 1922, p. 6). Não obstante, foi um dos mais proeminentes professores da instituição, com um desempenho particularmente assinalável no exercício de funções executivas e na reflexão sobre a vocação da instituição.

A cadeira de História Universal Filosófica era herdeira de um tradição consolidada no século XVIII, marcada por orientações nem sempre coincidentes, que passavam pela tentativa de identificação dos princípios da evolução histórica; pela determinação do papel desempenhado por cada povo no suposto progresso da humanidade; pela pretensão da descoberta de leis gerais do desenvolvimento histórico; e, de alguma forma, pela previsão do destino do homem. Tinha o nome de Voltaire inscrito no assento de paternidade. Porém, para o iluminista, essa área do saber não representaria mais do que a adoção de um processo crítico de construção do conhecimento histórico que, pondo de lado quaisquer constrangimentos, de autoridade ou tradição, erguer-se-ia livre como um produto apenas do labor do historiador.

Apropriando-se da expressão "Filosofia da História", mas não do significado que Ihe estava associado, Hegel considerava-a como uma resenha da história universal. Destilando algumas concepções presentes em trabalhos de filósofos alemães que o precederam, com destaque para Herder, Kant, Schiller e Fichte, em 1822-1823, proferiu uma série de conferências que estiveram na base da publicação da sua obra Filosofia da História (HEGEL 1995). Ela consistia numa história universal da humanidade, imbuída de uma crença de progresso que se distendia desde os momentos mais remotos até ao período contemporâneo.

Já em pleno século XIX, com o positivismo, corrente de pensamento teorizada por Auguste Comte, procurou aplicar-se ao processo histórico a mesma metodologia de trabalho e de interpretação que se aplicava aos processos naturais. Nesse sentido, vários positivistas conferiram à Filosofia da História ou à História Universal Filosófica a intenção da descoberta de leis gerais que regessem o curso dos acontecimentos. R.G. Collingwood sintetiza essa evolução: "em cada um destes exemplos, há uma concepção filosófica que orienta a concepção de filosofia da história: para Voltaire, filosofia significava um pensamento crítico e independente; para Hegel, significa um pensamento acerca do mundo, na sua totalidade; para o positivismo do século XIX, significa a descoberta de leis uniformes" (COLLINGWOOD 1989, p. 7). Talvez o mais destacado apóstolo do positivismo em Portugal tenha sido Teófilo Braga, quem, em 1872, ingressou no corpo docente do Curso Superior de Letras, onde fez escola e criou discípulos, entre os quais importa destacar Consiglieri Pedroso. 
O programa que Levy Maria Jordão apresentou para a cadeira de História Universal Filosófica para o ano letivo de 1862-1863 tinha como título "Curso de Filosofia da História". Concebendo a história como a "ciência dos fatos" e a filosofia como a "ciência das ideias", entendia que a disciplina que lecionava era a síntese desses dois elementos. Revelando influências hegelianas e comtianas, considerava, tal como o filósofo alemão, a existência de três géneros históricos: primitivo, reflexivo e filosófico. Por outro lado, tal como o francês, admitia a existência de leis que presidiam o desenvolvimento da humanidade.

Já o programa de História Universal Filosófica do ano letivo de 18651866 foi da autoria de Jaime Moniz, que revelou uma concepção distinta da apresentada pelo seu predecessor. Com efeito, numa abordagem que tinha por base uma ideia de história da civilização, o programa começava por incidir sobre as noções e princípios elementares da ciência e o estado em que na época se encontrava o conhecimento sobre o Antigo Egito, contemplando conteúdos apenas desse período da história, pela alegada impossibilidade de, apenas num ano letivo, percorrer conjuntamente todas as civilizações (MONIZ 1865, p. 11). Incidia depois na origem dos egípcios e sua relação com os povos e territórios que os circundavam. Seguiam-se três pontos extensos relativos aos diversos períodos da História do Egito Antigo. Por último, surgia um capítulo no qual era feita uma abordagem temática das suas instituições e costumes; da literatura, filosofia e conhecimento científico; da arte, arquitetura, escultura; e da religião. É provável que noutros anos letivos o programa da cadeira de 166 Jaime Moniz tenha incidido sobre períodos distintos da história da civilização ou que até tenha sido abordada de forma sintética a história de várias civilizações. A ausência da larguíssima maioria dos programas e sumários das cadeiras dificulta a elaboração de uma leitura aprofundada sobre a evolução dos conteúdos ministrados.

Com eloquência e graça, Francisco Lopes Vieira de Almeida afirmou que um programa é "uma tabuleta de um estabelecimento de ensino. E não pode atribuir-se-lhe muito maior valor. Por ele vagamente se conhece o que lá dentro existe. Revela certo, o intuito do legislador, o espírito que a ele presidiu. Mais nada" (ALMEIDA 1911, p. 75-76). Acresce que, tal como uma prescrição ou uma declaração de intenções, esse tipo de documentos nada diz sobre o que efetivamente aconteceu. A existência de séries sistemáticas com outros registos sobre as aulas, como apontamentos dos alunos ou sumários feitos pelos professores, contribuiria para ampliar o conhecimento sobre o que efetivamente era lecionado. Uma portaria de 30 de setembro de 1865 determinava o envio dos sumários das cadeiras para o Ministério do Reino, mas essa obrigação parece não ter sido cumprida (AGUILAR 1939, p. 299).

Em Paris foi criada em 1853 uma cadeira denominada História de França, na Escola Normal Superior, que, em 1862, seria transformada numa cadeira com a designação mais geral de História. Tal como em Portugal, na Dinamarca, na Finlândia, na Noruega, na Suíça, na Bielorrússia, na Escócia, na Hungria e em Chipre, as cadeiras de história tinham agregada uma explícita denominação nacional (PORCIANI 2006, p. 47-48). 
Os três programas conhecidos para a cadeira de História Pátria e Universal que foram elaborados por Rebelo da Silva (1860-1861, 1865-1866 e 18701871), foram sendo sucessivamente alargados, no quadro de uma concepção de história liberal na qual os conceitos de nação e civilização europeia ocupavam um lugar destacado. Estruturalmente nacionalistas, apresentam-se como exercícios de história da civilização, privilegiando numas ocasiões uma perspectiva geral da evolução histórica da Europa Ocidental e procurando noutras integrar a história de Portugal no todo europeu (MATOS 1998, p. 178). O programa do ano letivo de 1860-1861 era centrado na história de Portugal, recorrendo à história universal apenas de forma preambular para enquadrar alguns acontecimentos específicos do percurso pátrio. Explorando as origens da nacionalidade, exaltava a ação política de $\mathrm{D}$. Afonso Henriques, dando depois relevo a momentos cruciais, como 1383-1385 ou 1640. Esse programa parece ter sido forjado como uma arma para os combates a travar no presente, como antídoto para a ameaça iberista que se fazia sentir no início da segunda metade dos Oitocentos e contra a qual militava ativamente o professor (FREITAS 1999, p. 12). Já o programa de 18651866, que recebeu a designação de «A civilização na Europa nos séculos XVII e XVIII», dividia-se em quatro partes, consagrando apenas a última à história de Portugal. Com uma abordagem sociopolítica, em que se traçavam quadros sincrônicos, procurava comparar a marcha da humanidade em diferentes regiões do globo. O programa de 1870-1871 apresentava-se muito mais detalhado, mas se centrava na história de Portugal. Sob uma perspectiva cronológica, assente na sequência dos vários reinados, procedia a uma abordagem em que a história universal fornecia pistas de interpretação para a história de Portugal.

Augusto Soromenho lecionou a cadeira de História Pátria e Universal entre 1871 e 1878, desconhecendo-se a existência dos programas elaborados por ele. Coube posteriormente ao positivista Consiglieri Pedroso o magistério da cadeira. Na enumeração das matérias que haveria de ensinar no ano letivo de 1885-1886, ostentava uma concisão excessiva, plasmando-se apenas em meia página manuscrita um programa vago, no qual predominavam temas gerais, referentes a grandes épocas da história da civilização. Com uma apresentação descuidada, contrastava na extensão, na organização, no detalhe e na clareza com os programas anteriormente apresentados por Rebelo da Silva. Contrastava igualmente com programas de cadeiras análogas que, na mesma época, eram ministradas em estabelecimentos de ensino superior da Espanha.

Ingressando no corpo docente em 1872, Teófilo Braga integrou o contingente de professores que em 1910 transitaram para o quadro da Faculdade de Letras. Não obstando o fato de ter lecionado essencialmente cadeiras de Literatura, o papel que desempenhou na historiografia portuguesa não deve ser descurado. Sem entender a história como instrumento de propaganda, via no conhecimento do passado um recurso indispensável para o progresso do país, que passaria pela instauração de um regime republicano. Militante de primeira linha nessa causa, produzia naturalmente uma leitura antimonárquica e anticlerical dos acontecimentos. No seu heterodoxo positivismo, justificava a manutenção da independência fundamentando-a num determinismo étnico, que Ihe permitia 
sustentar a teoria de uma nacionalidade natural (MATOS 1998, p. 109-110, 321325). Invocava ainda o testemunho dos grandes vultos do passado e colocava-o ao serviço do reforço de novos consensos nacionais e sociais (HOMEM 1989).

Em 1881, dois anos depois de ter iniciado funções como professor, Consiglieri Pedroso publicou o seu Compêndio de História Universal. Nessa obra, definia a história como a "ciência que descreve os factos, que se passam no seio das sociedades humanas civilizadas, no tempo e no espaço, e estuda, tanto quanto possível, as leis que as regem" (PEDROSO 1884, p. 9). O livro continha uma concepção teórica positivista, evolucionista e eurocêntrica, que deveria pautar também as suas aulas, visto que, apesar de se destinar ao ensino liceal, a sua leitura também era recomendada aos alunos do Curso Superior de Letras.

Pela análise dos conteúdos curriculares das restantes cadeiras verifica-se a prevalência de abordagens eminentemente historicistas nas primeiras duas décadas de funcionamento da instituição. O ensino ministrado consistia, quase exclusivamente, numa introdução às temáticas que em pouco transcenderia a resenha dos momentos mais marcantes da evolução das respectivas áreas do saber. No entanto, a partir do final da década de setenta, com a criação das cadeiras de Língua e Literatura Sânscrita e Filologia Comparada, a cargo, respectivamente, de Vasconcelos de Abreu e Adolfo Coelho, verificou-se o reforço dos conteúdos relacionados com as línguas e literaturas, assistindo-se, paralelamente, à diluição da preponderância da história nos conteúdos programáticos das outras disciplinas.

168 Como constatou Vitorino Magalhães Godinho, o crocitante drama do ensino superior em Portugal, no século XIX, foi o divórcio entre ele e a investigação historiográfica, que era produzida essencialmente fora dos seus estabelecimentos, muitas vezes por autodidatas, como Alexandre Herculano, Oliveira Martins, Alberto Sampaio, Gama Barros, entre outros (GODINHO 1971, p. 244). Como corroboração dessa afirmação, registe-se que o Curso não teve qualquer centro organizado de investigação; a utilização da sua limitada biblioteca esteve vedada aos alunos; nenhum livro ou periódico foi publicado sob a sua chancela. Sem meios para acolher ou desenvolver trabalhos de investigação, foi sobretudo um estabelecimento vocacionado para a divulgação. Os seus docentes e discentes que se dedicaram à produção historiográfica, fizeram-no noutros contextos.

Entre os alunos que se vieram a impor como nomes representativos da historiografia portuguesa deve referir-se o de António Enes, autor de uma História de Portugal que contou, entre outras, com as colaborações do seu condiscípulo Luciano Cordeiro. Também Damião Peres, que veio a ser professor das Faculdades de Letras das Universidades do Porto (1919-1928) e de Coimbra (1931-1959), viria a dirigir uma História de Portugal. Na redação dessa obra colaboraram Queirós Veloso, Oliveira Ramos, David Lopes e Newton de Macedo, que também passaram pelas cadeiras do Curso. No domínio das obras coletivas tem ainda interesse a História da colonização portuguesa do Brasil dirigida por Carlos Malheiro Dias, por ocasião da celebração do centenário da independência do Brasil, e que teve como colaborador o seu companheiro de escola Esteves Pereira. 
Para além dos autores das sumas históricas já mencionados, importa referir outros que, tendo sido igualmente alunos da instituição, produziram trabalhos historiográficos que versaram sobre aspectos particulares. No ramo da cultura, devem assinalar-se as obras de José Maria da Silva Pessanha e Guilherme Joaquim Moniz Barreto, que se debruçaram sobre a história da arte e da literatura, respectivamente. No âmbito da historiografia da expansão distinguiram-se Luciano Cordeiro, David Lopes e Henrique Lopes de Mendonça. No domínio da história militar surgem os esforços de Cristóvão Aires, classificados por Oliveira Marques como "indigestos" e "caóticos" (MARQUES 1988, p. 39). Na esfera da história local, cumpre lembrar o trabalho paradigmaticamente pitoresco de Júlio Castilho: Lisboa antiga.

Em seu amplo polimorfismo intelectual, Fidelino de Figueiredo foi, para além de historiador, filósofo e crítico literário. Coube-lhe o mérito de ter sido o grande impulsionador da criação da Sociedade Portuguesa de Estudos Históricos, que contou entre os seus promotores com Cristóvão Aires e David Lopes. Dirigiu ainda a Revista de História (1912-1928), na qual colaboraram os seus condiscípulos Diogo do Prado Coelho, Pedro Azevedo, David Lopes e Francisco Lopes Vieira de Almeida.

Nos domínios da "construção e da problematização em história, prenunciando, em certa medida a história-problema que viria a ser pedra de toque com a História Nova" (MENDES 1998, p. 196), como refere Amado Mendes, não pode deixar de mencionar-se o nome de Vieira de Almeida. A sua dissertação, que foi das últimas a ser defendidas antes de o Curso se transmutar em Faculdade de Letras, intitulava-se História - significado e função (ALMEIDA 1911). Nela, o autor fez uma riquíssima reflexão sobre a disciplina, o seu objecto e o seu método. Categorizou os diversos tipos de documentos, clarificou a diferença entre eles e os fatos, avaliando ainda a importância dos acontecimentos singulares e o papel das individualidades no curso da história.

O legado do Curso Superior de Letras consistiu principalmente no alargamento e autonomização daquilo que Pierre Bourdieu classificou como o campo científico. Com efeito, a sua existência impôs-se como referencial para as instituições apostadas na divulgação historiográfica. Acresce que a formação ministrada reforçou legitimidades, caucionou méritos e outorgou poder simbólico, por via da credenciação que conferia; isso num período em que se consolidou a tendência de segregação do mérito intelectual como algo que estava cada vez mais dependente da obtenção de um título académico. (BOURDIEU 2003, p. 20-21).

O pensamento historiográfico, como qualquer forma de pensamento, é o produto de uma evolução histórica. Também o desenvolvimento do sistema de ensino resulta de um percurso, nem sempre claro, no qual se confrontam disciplinas, se debatem concepções de ciência e, ainda que de forma não consciente, projetos de sociedade. Sujeitos a condicionalismos de ordem política, ideológica, cultural, social e económica, a produção científica e o ensino veem os seus resultados depender dessa série de constrangimentos. Ajustando-se em cada momento às circunstâncias, construindo-se nesse exercício, o Curso Superior de Letras, por mais acanhados que tenham sido os recursos à sua disposição e por mais 
limitada que tenha sido a sua ação, desempenhou uma função significativa no domínio da vulgarização histórica, contribuiu para reforçar o seu reconhecimento social como disciplina autônoma e concorreu para a gradual profissionalização dos historiadores, ofício que se legitimava por via das exigências, que iam se impondo gradualmente, de rigor heurístico e hermenêutico.

\section{Referências bibliográficas}

ABREU, J. M. de. Projeto de Lei. Apresentado às Cortes pelo senhor deputado Dr. José Maria de Abreu, na sessão de 18 de Abril de 1857. O Instituto, vol. VI, no 3, p. 25, 10 de Maio de 1857.

AGUILAR, M. B. de A. O Curso Superior de Letras (1858-1911), Lisboa: s.n., 1939.

ALMEIDA, F. L. V. de. História (significado e função). Tese para o 40 ano do Curso Superior de Letras - Secção de Geografia e História - 1910. Coimbra: Imprensa da Universidade, 1911.

BOURDIEU, Pierre. Os usos sociais da ciência. Por uma sociologia clínica do campo científico. São Paulo: Editora da Unesp, 2003.

CASTILHO, J. de. Lisboa Antiga. Coimbra: Imprensa da Universidade, 1884-1890.

COELHO, A. Alexandre Herculano e o ensino público, Lisboa: J. A. Rodrigues e Ca, 1910. O ensino Histórico, filológico e filosófico em Portugal até 1858, Coimbra. O Instituto, vol. XLVII, no 8, p. 467-468, agosto de 1900.

COLLINGWOOD, R. G.. A ideia de História. Lisboa: Editorial Estampa, 1989.

ENES, A. et. al. História de Portugal. Lisboa: Empresa Literária de Lisboa, 1876-1877.

DIAS, C. M. (dir.). História da colonização portuguesa do Brasil. Porto: Litografia Ferreira Pinto, 1921-1924.

FIGUEIREDO, F. de. O espírito histórico. Lisboa: Tipografia da Cooperativa Militar, 1910.

FREITAS, P. M. L. de. Rebelo da Silva, discípulo de Herculano e professor do Curso Superior de Letras de Lisboa. Alexandre Herculano. Liberalismo e Romantismo. Santarém: Escola Superior de Educação de Santarém, p. $123-134,1999$.

GODINHO, V.M. Ensaios III. Sobre Teoria da História e Historiografia. Lisboa: Livraria Sá da Costa, 1971.

HEGEL, Georg Wilhelm Friedrich. Filosofia da História. Brasília: Editora Universidade de Brasília, 1995.

HOMEM, Amadeu Carvalho. A ideia republicana em Portugal. O contributo de Teófilo Braga. Coimbra: Minerva, 1989. 
MACEDO, J. B. de. Alexandre Herculano. Polémica e Mensagem. Lisboa: Bertrand, 1980.

MARQUES, A. H. de O. Ensaios de historiografia portuguesa. Lisboa: Palas, 1988.

MATOS, S. C. Historiografia e memória nacional. 1846-1898. Lisboa: Colibri, 1998.

MENDES, J. A. Desenvolvimento e estruturação da historiografia portuguesa, História da História em Portugal, Luís Reis Torgal, José Amado Mendes e Fernando Catroga, v.I - A História através da História. Lisboa: Temas e Debates, 1998, Vol. I.

MONIZ, Jaime. Quinta cadeira. História Universal Filosófica. Programa das cadeiras do Curso Superior de Letras para o ano lectivo de 18651866. Lisboa: Imprensa Nacional, 1865.

PEDRO V D. Escritos de El-Rei D. Pedro V. Coligidos e publicados pela Academia das Ciências de Lisboa. Coimbra: Imprensa da Universidade, 1930.

PEDROSO, Zófimo Consiglieri. Compêndio de História Universal. Lisboa: Magalhães e Moniz Editora, 1884.

PEREIRA, F. M. E. Elogio histórico de Jaime Constantino de Freitas Moniz, Memórias da Academia das Ciências. Nova série T. XIV, p. 6, 1922.

PERES, Damião (dir.). História de Portugal. Barcelos: Portucalense Editora, 1928-1954.

PORCIANI, I., Mapping Institutions, Comparing Historiographies: the Making of an European atlas Atlas. Storia della Storiografia. no 50, p. 27-58, 2006.

SILVA, L. A. R. da. História de Portugal nos Séculos XVII e XVIII. Lisboa: Imprensa Nacional, 1860-1871, Vol. VI.

VALE, MI M del. Programa de História Universal. Madrid, 1882.

VALÊNCIA, M. P. Programa de la asignatura de Historia de España. Madrid, 1877.

VILHENA, J. D. Pedro V e o seu reinado. Coimbra: Imprensa Universitária, 1921, Vol. II. 